\title{
Action on AMD. Optimising patient management: act now to ensure current and continual delivery of best possible patient care
}

Eye (2012) 26, S1; doi:10.1038/eye.2011.342 and logistics was provided by Novartis. A report was generated by the meeting, which formed the basis of this document. Novartis has had the opportunity to review this document for technical accuracy but has had no editorial input. We thank Sue Harris from ApotheCom who provided medical writing support on behalf of Novartis Pharmaceuticals.

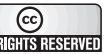

This work is licensed under the Creative Commons AttributionNonCommercial-No Derivative Works 3.0 Unported License. To view a copy of this license, visit http://creativecommons.org/licenses/by-nc$\mathrm{nd} / 3.0 /$

\section{Statement from the College of Optometrists}

The College of Optometrists welcomes the publication of Action on AMD, which gives examples of good practice across the country. We welcome the multidisciplinary nature of both the expert group that produced the document and the suggested solutions to the capacity issues facing the Hospital Eye Service. We hope these will improve access to treatment for patients with this blinding condition.

\section{Statement from the Royal College of Ophthalmologists}

The Royal College of Ophthalmologists (RCOphth) welcomes the prominence given in Action on $A M D$ to the importance of fast-track patient referral systems from primary care. This, combined with prompt commencement of therapy in ophthalmology care and regular monthly follow-up, is in accordance with NICE guidance and RCOphth guidelines. The document gives examples of service innovations, and further quality improvements in AMD patient care are encouraged. The College believes that AMD patients are best evaluated and treated by an ophthalmologist with expertise in this condition, and it values multidisciplinary teamwork.

\section{(1) NOVARTIS}

